\title{
Vibration Analysis of Plates by the Superposition Method
}




\title{
SERIES ON STABILITY, VIBRATION AND CONTROL OF SYSTEMS
}

\author{
Series Editors: Ardéshir Guran \& Daniel J. Inman
}

\begin{abstract}
About the Series
Rapid developments in system dynamics and control, areas related to many other topics in applied mathematics, call for comprehensive presentations of current topics. This series contains textbooks, monographs, treatises, conference proceedings and a collection of thematically organized research or pedagogical articles addressing dynamical systems and control.

The material is ideal for a general scientific and engineering readership, and is also mathematically precise enough to be a useful reference for research specialists in mechanics and control, nonlinear dynamics, and in applied mathematics and physics.
\end{abstract}

\section{Selected Forthcoming Volumes}

Series A. Textbooks, Monographs and Treatises

Adaptive Control of Nonlinear Systems

Authors: R. Ghanadan, A. Guran and G. Blankenship

Series B. Conference Proceedings and Special Theme Issues

Acoustic Interactions with Submerged Elastic Structures

Part II: Propagation, Ocean Acoustics and Scattering

Editors: A. Guran, G. Maugin and J. Engelbrecht

Part III: Acoustic Propagation and Scattering, Wavelets and

Time-Frequency Analysis

Editors: A. Guran, A. de Hoop and D. Guicking

Part IV: Non-destructive Testing, Acoustic Wave Propagation and Scattering

Editors: A. Guran, A. Boström, A. Gerard and G. Maze

\section{Published Volumes in Series A}

Vol. 1 Stability Theory of Elastic Rods Author: T. Atanackovic

Vol. 2 Stability of Gyroscopic Systems Editors: A. Guran, A. Bajaj, Y. Ishida, G. D'Eleuterio, N. Perkins and C. Pierre

Vol. 3 Vibration Analysis of Plates by the Superposition Method Author: Daniel J. Gorman 


\title{
Vibration Analysis of Plates by the Superposition Method
}

\author{
Daniel J. Gorman \\ Department of Mechanical Engineering \\ University of Ottawa
}




\section{Published by}

World Scientific Publishing Co. Pte. Ltd.

P O Box 128, Farrer Road, Singapore 912805

USA office: Suite 1B, 1060 Main Street, River Edge, NJ 07661

UK office: 57 Shelton Street, Covent Garden, London WC2H 9HE

\section{British Library Cataloguing-in-Publication Data}

A catalogue record for this book is available from the British Library.

\section{VIBRATION ANALYSIS OF PLATES BY THE SUPERPOSITION METHOD}

Copyright $\odot 1999$ by World Scientific Publishing Co. Pte. Ltd.

All rights reserved. This book, or parts thereof, may not be reproduced in any form or by any means, electronic or mechanical, including photocopying, recording or any information storage and retrieval system now known or to be invented, without written permission from the Publisher.

For photocopying of material in this volume, please pay a copying fee through the Copyright Clearance Center, Inc., 222 Rosewood Drive, Danvers, MA 01923, USA. In this case permission to photocopy is not required from the publisher.

ISBN 981-02-3681-6

This book is printed on acid-free paper.

Printed in Singapore by Uto-Print 


\section{TO THE MEMORY \\ $O F$ \\ MY PARENTS LAWRENCE AND ELLEN (ENRIGHT) GORMAN \\ AND THEIR BELOVED DAUGHTERS \\ BETTY AND AL}




\section{This page is intentionally left blank}




\section{PREFACE}

The subject of free vibration analysis of thin plates is one which extends well back into the last century. The development of metal alloys and other high strength materials permits the wide use of thin plates in the modern industrial world. In many instances, where structures are subjected to time-varying forces, the ability of designers to compute, in advance, the natural frequencies and mode shapes of these thin plates is of critical importance. This is true, not only in the aerospace industry, but applies to many civil structures as well. The range of industrial problems where plate free vibration analysis is required varies from design of offshore petroleum exploration equipment to thin electronic circuit boards.

A vast number of publications have appeared in the literature related to thin plate free vibration analysis. Nevertheless, historically, there have been two principal approaches taken toward resolving these problems. The most popular traditional approach is based on energy considerations and the method of analysis is known as the Rayleigh-Ritz method. In order to exploit this method one must choose an appropriate set of functions to represent the plate mode shape. These functions must also satisfy certain boundary conditions of the problem under study. Mode shapes are usually represented by an infinite series of functions, but only a finite number of functions can be employed in the analysis. It is found that frequencies thereby obtained generally represent upper limits for the actual frequencies.

An alternate approach to plate free vibration analysis has been the use of numerical methods to obtain solutions which satisfy, as closely as possible, the plate governing differential equation and the prescribed boundary conditions. There is no doubt that with the advent of the highspeed digital computer the use of finite element methods has become the most popular numerical approach. This method is widely utilized in modern industry. 
During the past decade and a half the author and his associates have been involved in development and exploitation of a new analytical approach to rectangular plate free vibration analysis. The method of analysis is referred to as the "Superposition Method". One begins by superimposing a set of judiciously selected forced vibration problems for which exact series solutions are known. These are referred to as building blocks. They are usually driven by harmonic moments or vertical edge reactions distributed along one of the boundaries. With the building blocks superimposed, unknown Fourier driving coefficients appearing in their solutions are adjusted so as to satisfy the prescribed boundary conditions for the problem of interest.

The superposition technique provides a welcome alternative to the traditional Rayleigh-Ritz and finite element methods, and one which is becoming more and more attractive. Of the three techniques, only the superposition and Rayleigh-Ritz methods provide solutions based on continuum mechanics. Despite this shortcoming, the finite element method is usually resorted to when structures are so complicated that a solution based on continuum mechanics is virtually impossible to achieve.

Two of the most obvious advantages of the superposition method may be listed as follows:

1. It is the only one of the three methods which provides solutions which satisfy the governing differential equation exactly throughout the entire domain of the plate.

2. The problem of trying to select appropriate series of functions to represent plate lateral displacement when utilizing the RayleighRitz method often becomes a formidable one. In fact, in the case of plates with free edges, it has been demonstrated that fully appropriate functions do not exist. This is because mathematical formulation of free edge boundary conditions involves mixed spatial derivatives of the plate lateral displacement. 
It is a great strength of the superposition method that no selection of such functions is required. In fact, the solution is self contained in that computed plate lateral displacements are generated from within and are based entirely on analytical solutions to the plate governing differential equation.

The objective set forth in this book is to make this highly accurate analytical method available to all potential users in the field of mechanical vibration. It is not the objective to include vast arrays of pre-computed eigenvalues. This has been taken care of by numerous publications in the existing literature which are referred to herein. It is almost certain that a much more general adoption of this powerful analytical technique, with its numerous advantages, has been delayed by the lack of a carefully prepared text explaining, in detail, how the method functions and how it can be exploited. This book is prepared with a view to filling this need.

The vast capabilities of the superposition method were not originally foreseen. It is found, for example, that in addition to rectangular plates it can be extended to handle straight edged plates, such as triangular plates, parallelogram plates, orthotropic plates, laminated plates, etc. All of these capabilities are described in the book.

In Chapter 1, the basic theory leading to solutions for rectangular plate free vibration problems is explained. Practical instruction is provided with regard to how best to prepare computer routines for efficient exploitation of this method. Solution to a typical free vibration problem is described in detail for illustrative purposes. Recognizing how easily the treatment of isotropic plate problems, as discussed in Chapter 1, can be extended to handle orthotropic plate problems, Chapter 2 is devoted to the analysis of orthotropic plates. Treatment of orthotropic plates is deliberately introduced at this early stage so that both isotropic and orthotropic plate theory can be applied to problems of the remaining chapters. 
Experience has shown that the method is ideally suited for resolving problems of plates with elastic edge support. It also readily handles problems involving plates with point supports on their lateral surface and attached masses. These two families of problems are discussed in Chapters 3 and 4, respectively. Plates with mixed boundary conditions are considered in Chapter 5 while the problem of handling nonrectangular straight-edged plates is the subject of Chapter 6.

In Chapter 7 the resolution of problems with uniform in-plane forces is discussed in detail. It is shown how this family of problems is extended to include the rectangular plate buckling problem. Chapter 8 explains how the superposition method is readily exploited to handle Mindlin thick plate problems. The free vibration of composite plates is the subject of Chapters 9. Treatment of these topics by the superposition method is a relatively recent phenomenon, but it is found that, again, the method works quite well.

The author has found, however, that even though the traditional superposition technique works very well for the much more complicated vibration problems of thick Mindlin plates and laminated plates the amount of effort required on the part of the analyst is greatly increased. Accordingly, he has explored a slightly modified method for handling such problems. The only difference related to these modified approaches centres around the manner in which the basic "Building Block" solutions are obtained. Otherwise, the procedures are identical to those of the previous chapters. It is shown how this alternate approach employing the Galerkin procedure can lead to drastic reductions on the effort required by the analyst.

Chapter 10 is devoted to the determination of response of undamped rectangular plates to steady state harmonic excitation by lateral forces or bending moments. These forces or moments may be concentrated or distributed. It is explained how the material of the earlier chapters may be exploited to ensure that desired boundary conditions are satisfied. 
Chapter 11, the final chapter, is left open for discussion of some interesting auxiliary problems amenable to solution by the superposition method. These are problems which do not quite fall into the categories of problems related to the previous chapters. It is explained, for example, how the superposition building block approach functions equally well when searching for stress functions related to general plane stress problems. Procedures for analysing rectangular plates resting on line supports of arbitrary configuration are described. It is also explained how the same procedures are employed to obtain rapid but quite accurate solutions to problems involving plates with discontinuities in edge support. The subject of analysing continuous multi-span plates is also introduced.

In each chapter results are tabulated for typical problems treated therein. In this way the reader will have accurate data against which his or her results may be compared. The ability to make such comparisons is essential so that the correct functioning of newly prepared computer routines can be verified.

Many people have contributed toward the realization of this book in one fashion or another. Their names are much too numerous to recognize here on an individual basis. Nevertheless, the author would like specifically to acknowledge the invaluable assistance of Dr. K.G. Gupta who prepared all of the original drawings for the figures appearing in the text. His critical attention to detail and innovative suggestions are deeply appreciated. The author would like also to recognize the vital contribution of Ms. Josée Rocheleau who typed all of the manuscript. 


\section{This page is intentionally left blank}




\section{NOMENCLATURE}

\section{Listing of frequently used symbols}

a,b

D

E

f

G

$\mathrm{h}$

K

k

$\mathrm{K}_{\mathrm{L}}$

$\mathrm{K}_{\mathrm{R}}$

$\mathrm{K}^{*}$

M

$\mathrm{M}_{\mathrm{xy}}$

$M_{x}, M_{y}$

$M_{\xi}, M_{\eta}$

$M_{0}$

$M_{R}$

$N_{x}, N_{y}$

$\mathrm{N}_{\mathrm{xy}}$

$P$

$\mathrm{P}^{*}$

$P_{x}$

$P_{\xi}$

$Q_{x}, Q_{y}$

$\mathrm{S}$

$\mathrm{T}$

$\mathrm{u}, \mathrm{v}$

$\mathrm{u}^{*}, \mathrm{v}^{*}$

$\mathrm{V}$

$\mathrm{V}_{\boldsymbol{\xi}}$

$V_{\eta}$

$\mathrm{V}_{\mathrm{o}}$
Rectangular plate edge lengths

Plate flexural rigidity $=\mathrm{Eh}^{3} / 12\left(1-v^{2}\right)$

Young's modulus of elasticity

Plate vibration frequency, $\mathrm{H}_{\mathrm{z}}$

Modulus of elasticity in shear

Plate thickness

Number of terms in series expansions

Basic lateral elastic stiffness

Dimensionless lateral elastic stiffness

Dimensionless rotational elastic stiffness

Dimensionless local spring stiffness

Bending moment

Twisting moment

Moments associated with $\mathrm{x}$ and $\mathrm{y}$, directions

$M_{x} a / D$, and $M_{y} b^{2} / a D$, respectively.

Concentrated harmonic bending moment

Ratio of attached mass to mass of plate

In-plane normal stress resultants

In-plane shear stress resultant

Amplitude of harmonic concentrated force

$-2 \mathrm{P} \mathrm{b}^{3} / \mathrm{a}^{2} \mathrm{D}$

Plate total in-plane force in " $\mathrm{x}$ " direction

$\mathrm{P}_{\mathrm{x}} \mathrm{b} / \mathrm{D}$

Shear forces associated with $\mathrm{x}$, and $\mathrm{y}$, directions

Plate edge length-to-thickness ratio, $a / h$

Basic torsional elastic stiffness

Coordinates of plate point support

$(1-u)$, and $(1-v)$

Plate vertical edge reaction

$\mathrm{V} \mathrm{a} / \mathrm{D}$

$\mathrm{V} \mathrm{b} / \mathrm{a} \mathrm{D}$

Concentrated harmonic edge reaction 
Plate lateral displacement divided by "a"

$\mathrm{x}, \mathrm{y} \quad$ Basic plate coordinates

$\mathrm{z}$

Coordinate running downward from plate mid-plane

Symbols associated with Orthotropic Plates

$\mathrm{D}_{\mathrm{x}}, \mathrm{D}_{\mathrm{y}}$

$\mathrm{E}_{\mathrm{x}} \mathrm{h}^{3} /\left[12\left(1-v_{\mathrm{x}} v_{\mathrm{y}}\right)\right], \mathrm{E}_{\mathrm{y}} \mathrm{h}^{3} /\left[12\left(1-v_{\mathrm{x}} v_{\mathrm{y}}\right)\right]$

DHX, DHY $H / D_{x}$, and $H / D_{y}$

$\mathrm{D}_{\mathrm{t}}$

$\mathrm{G}_{\mathrm{xy}} \mathrm{h}^{3} / 12$

$E_{x}, E_{y}$

$\mathrm{G}_{\mathrm{xy}}$

Young's Moduli associated with $\mathrm{x}$, and $\mathrm{y}$ directions

$2 \mathrm{H}$

Elastic modulus in shear associated with $\mathrm{x}, \mathrm{y}$ plane

$v_{\mathrm{y}} \mathrm{D}_{\mathrm{x}}+v_{\mathrm{x}} \mathrm{D}_{\mathrm{y}}+4 \mathrm{D}_{\mathrm{t}}$

\section{Greek Symbols}

$\xi, \eta$

$v$

$v_{\mathrm{x}}, v_{\mathrm{y}}$

$v_{\mathrm{x}}^{*}$

$v_{y}^{*}$

$v^{*}$

$v_{1}$

$v_{2}$

$v_{3}$

$\Psi_{\xi}, \Psi_{\eta}$

$\phi$

$\phi_{\mathrm{h}}$

$\kappa^{2}$

$\omega$

$\omega_{\mathrm{d}}$

$\epsilon_{\mathrm{x}}, \epsilon_{\mathrm{y}}$

$\lambda^{2}$

$\rho$

$\sigma_{\mathrm{x}}, \sigma_{\mathrm{y}}$
Dimensionless coordinates, $\mathrm{x} / \mathrm{a}$ and $\mathrm{y} / \mathrm{b}$

Poisson's ratio

Poisson ratios associated with $\mathrm{x}$, and $\mathrm{y}$ directions

$=2 \mathrm{H} / \mathrm{D}_{\mathrm{y}}-v_{\mathrm{y}}$

$=2 \mathrm{H} / \mathrm{D}_{\mathrm{x}}-v_{\mathrm{y}}$

$=(2-v)$

$=(1-v) / 2$

$=(1+v) / 2$

$=6 \kappa^{2}(1-v)$

Plate cross-section rotations associated with $\xi$, and $\eta$, directions

Plate aspect ratio, $\mathrm{b} / \mathrm{a}$

Plate thickness ratio, $\mathrm{h} / \mathrm{a}$

Mindlin shear correction factor

Circular frequency of free vibration

Circular frequency of forced vibration excitation

Linear strain related to $\mathrm{x}$, and $\mathrm{y}$, directions

Eigenvalue $=\omega \mathrm{a}^{2} \sqrt{\rho / \mathrm{D}}$

Mass of plate per unit area

Normal stresses in $\mathrm{x}$, and $\mathrm{y}$, direction 


\section{CONTENTS}

Preface $\ldots \ldots \ldots \ldots \ldots \ldots \ldots \ldots \ldots \ldots \ldots \ldots \ldots \ldots$ vii

Nomemclature $\ldots \ldots \ldots \ldots \ldots \ldots \ldots \ldots \ldots \ldots \ldots \ldots \ldots$ xiii

Chapter 1 Plate Vibration Analysis by the Method of

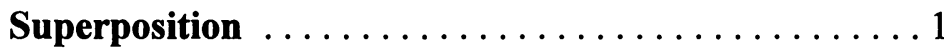

1.1 General Introduction to the Superposition Method $\ldots \ldots \ldots \ldots 1$

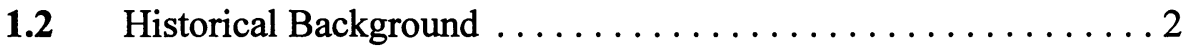

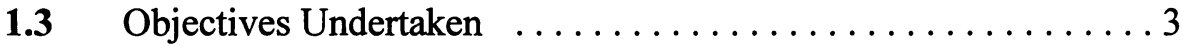

1.4 Detailed Illustrative Problem $\ldots \ldots \ldots \ldots \ldots \ldots \ldots \ldots$

1.5 Convergence Toward Exact Eigenvalues ........... 20

1.6 Verification Tests for the Eigenvalue Matrix $\ldots \ldots \ldots \ldots 21$

1.6.1 Boundary Verification Tests .............. 21

1.6.2 Matrix Element Continuity Test $\ldots \ldots \ldots \ldots \ldots \ldots 22$

1.6.3 Verification by Focusing on Submatrices ......... 23

1.7 Companion Solutions for the Illustrative Example . . . . . . . 23

1.7.1 Modes Fully Antisymmetric About the Central Axis of the Completely Free Plate . . . . . . . . . . 23

1.7.2 Modes Antisymmetric About the Central $\eta$ Axis and Symmetric about the Central $\xi$-axis. . . . . . . 24

1.8 General Solution for the Completely Free Plate . . . . . . . . . 24

1.9 Utilization of Prescribed Rotation Instead of Bending

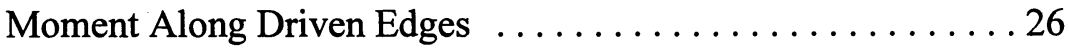

1.10 Practical Application of the Theory $\ldots \ldots \ldots \ldots \ldots \ldots 27$

1.11 Computer Program for Illustrative Problem. . . . . . . . . . . . 29

1.12 General comments on Program Listing of Appendix III . . . 32

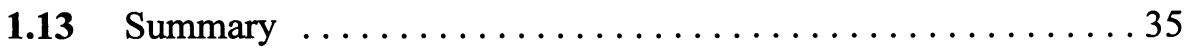

Chapter 2 The Vibration of Orthotropic Rectangular

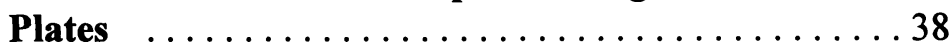

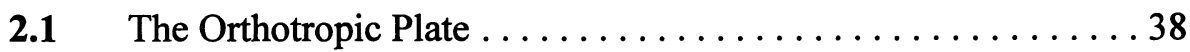

2.2 Elastic Properties of the Orthotropic Plate $\ldots \ldots \ldots \ldots \ldots$ 
2.3 Development of Orthotropic Plate Boundary Conditions . . . . 39

2.4 Development of the Equilibrium Equation $\ldots \ldots \ldots \ldots \ldots 4$

2.5 Solutions to the Governing Differntial Equation ........... 45

2.6 Brief Review of some Orthotropic Plate Problems

Resolved by the Superposition Method. . . . . . . . . 47



Chapter 3 Plates with Elastic Edge Support $\ldots \ldots \ldots \ldots \ldots 7$

3.1 Plates with Linear Lateral Elastic Edge Support. . . . . . . . . 58

3.2 Computed Eigenvalues for Plates with Uniform

Lateral Elastic Edge Support. . . . . . . . . . . . 66

3.3 Plates with Uniform Rotational Elastic Support

Along the Edges. ................... 70

3.4 Vibration of Plates with Combinations of Lateral

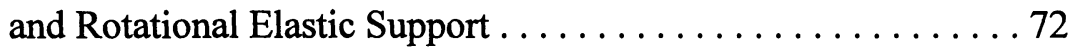

3.5 Plates with Arbitrarily Distributed Lateral and Rotational

Elastic Support Along the Boundaries. . . . . . . . . . . 74



Chapter 4 Point Supported Plates and Plates with

Attached Masses . . . . . . . . . . . . . . . . . 81

4.1 The completely Free Plate Resting on Point Supports . . . . . . 81

4.2 Presentation of Computed Results ................. . 95

4.3 Free Vibration of Plates with Point Support on the Edge . . . . 99

4.4 Free Vibration of Plates with Attached Masses . . . . . . . . . 99

4.5 Free Vibration of Plates Resting on Linear Elastic Springs . . 102

4.6 Review of Pertinent Publications . . . . . . . . . . . 103

4.6.1 Free Vibration of Point Supported Orthotropic Plates . . 106

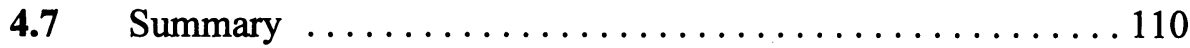

Chapter 5 Vibration of Pates with Mixed Boundary

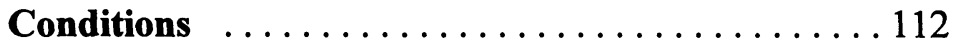

5.1 Free Vibration of a Plate with Clamped-simple

Support Along one Edge. . . . . . . . . . . . . . . 112

5.2 Plates with Discontinuities in Vertical Edge Reaction . . . . 118 
5.3 Computation of Eigenvalues . . . . . . . . . . . . . . . . 124

5.4 Free Vibration of Partially Clamped Cantilever Plates with Rigid Point Supports . . . . . . . . . . . . . . . 128

5.4.1 Development of the Eigenvalue Matrix .......... 135

5.4.2 Generation of Eigenvalues and Presentation of Computed Results ....................... 137

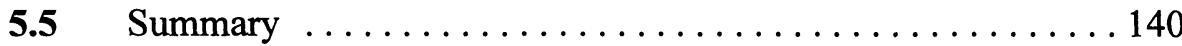

Chapter 6 Free vibration of non-rectangular straight-edged plates ............................ 142

6.1 Analysis of the Simply Supported Right Triangular Plate by the "Direct Driven Boundary" Approach ............ 143

6.2 Analysis of Straight-Edged Plates by the "Embedded Plate" Approach" ............................ 147

6.2.1 The Clamped-Simply Supported-Simply Supported Right Triangular Plate .................. 147

6.2.2 The Simply Supported-Free-Simply Supported Right Triangular Plate ...................... 152

6.2.3 Other Right Triangular Plates with One Free Edge . . 157

6.2.4 Right Triangular Plates with More Than One Free

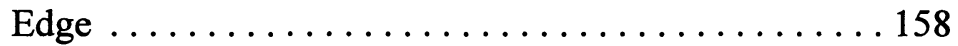

6.2.5 The Free Vibration of Isosceles Triangles . . . . . . 158

6.2.6 The Free Vibration of Rhombic Plates ......... 160

6.2.7 Free Vibration of the General Simply Supported Triangular Plate ....................... 162

6.2.8 Free Vibration of the Simply Supported Parallelogram Plate ................................. 170

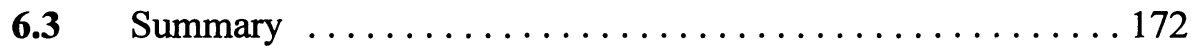

Chapter 7 Free Vibration and Buckling of Plates with In-Plane Forces ..................... 175

7.1 The Governing Differential Equation and Formulation of Boundary Conditions . . . . . . . . . . . . . . 175

7.2 The Simply Supported-Free-Clamped-Free Plate with Uniform In-Plane Forces 
7.2.1 Development of the Eigenvalue Matrix ...... 193

7.3 Buckling of Rectangular Plates Due to Uniform In-Plane Loading . . . . . . . . . . . . . . . 194

7.4 Buckling and Free Vibration Eigenvalues for the S-F-C-F Rectangular Plate. . . . . . . . . . . . . . . . . . 196

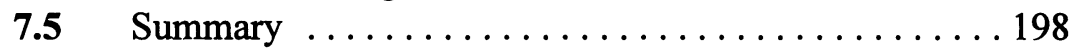

Chapter 8. The Vibration of Mindlin Plates . . . . . . . . . . 200

8.1 The Differential Equations and Boundary conditions Based on Mindlin Theory . . . . . . . . . . . . 201

8.2 Analysis of the Completely Free Mindlin Plate as an Illustravtive Problem . . . . . . . . . . . . . . . . 203

8.2.1 Generation of the Eigenvalue Matrix . . . . . . 226

8.2.2 Presentation of Computed Results . . . . . . . 228

8.3 Other Thick Plate Problems ................. 230

8.3.1 Free Vibration Analysis of Fully Clamped Mindlin Plates .................. 231

8.3.2 Free Vibration of Mindlin Plates Resting on Uniform Elastic Edge Support . . . . . . . 231

8.3.3 Generation of the Eigenvalue Matrix . . . . . . . 237

8.3.4 Presentation of Computed Results . . . . . . . . 242

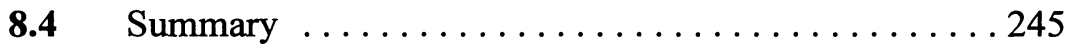

Chapter 9 Free Vibration of Laminated Plates . . . . . . . . . . 247

9.1 Free Vibration of Clamped Laminated Symmetric Cross-Ply Plates by the Superposition-Galerkin Method ......................... 248

9.1.1 Development of the Governing Differential Equations ................... 249

9.1.2 Analysis by the Conventional Superposition Approach ....................255

9.1.3 Analysis by the Superposition-Galerkin Approach ................... 260

9.1.4 Some Computed Results for the Fully Clampled Symmetric Cross-Ply Plate . . . . . . . . . 265 
9.2 Free Vibration of Clamped Laminated Antisymmetric Angle-Ply Plates by the Superpsition-Galerkin

Method ............................. 269

9.2.1 Governing Differential Equations .........270

9.2.2 Formulation of Boundary Conditions .......285

9.2.3 Development of Required Forced Vibration Solutions ....................286

9.2.4 Solution by the Galerkin Method. . . . . . . . . 290

9.2.5 Generation of Eigenvalue Matrix . . . . . . . . . 292

9.2.6 Presentation of Computed Results . . . . . . . . . 293

9.3 Summary ........................... 296

Chapter 10 The Forced Vibration of Plates. . . . . . . . . . . . 299

10.1 Plate Response to Distributed Bending Moments Along a Boundary .................... 300

10.2 Response of the Plate of Figure 10.1 to a Vertical Edge Reaction Along the Driven Edge. . . . . . . . . 304

10.3 Response of the Plate of Figure 10.1 to a Concentrated Harmonic Force Acting on the Driven Edge. . . . . . . 305

10.4 Response of the Plate of Figure 10.1 to a Concentrated Harmonic Bending Moment Acting on the Driven Edge.

10.5 Plate Response to an Internal Line Load Acting Parallel to one of the Boundaries ............. 308

10.6 Plate Response to an Internal Line Moment Acting Parallel to one of the Boundaries ............... 311

10.7 Plate Response to a Concentrated Harmonic Driving Force Located at an Arbitrary Position on the Lateral Surface .......................... 312

10.8 Plate Response to a Concentrated Harmonic Bending Moment Located at an Arbitrary Position on the Lateral Surface ............................ 312

10.9 Plate Response to a Transverse Harmonic Loading Distributed Along an Arbitrarily Oriented Straight line 313 
10.10 Plate Response to a Harmonic Bending Moment Distributed Along an Arbitrarily Oriented Straight Line ... . . . . . . . . . . . . . . . . . . . . . . 314

10.11 Plate Response to an Arbitrarily Distributed Transverse Lateral Harmonic Loading . . . . . . . . . . . 315

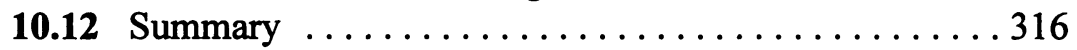

Chapter 11 Some Additional Applications of the Superposition Method. ........................ 318

11.1 Computation of Stresses Induced in a Thin Rectangular Membrane by Corner Loading . . . . . . . . . 318

11.2 Free and Forced In-Plane Vibration of Rectangualar Plates ............................ 325

11.3 Alternative Approach to Free Vibration Analysis of Plates with Discontinuities in Edge Support or Irregular Line Support . . . . . . . . . . . . . . . . . . 329

11.4 Free Vibration Analysis of Continuous Plates. . . . . . 334

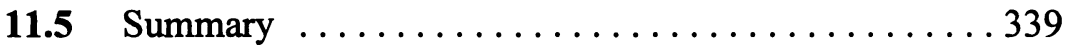

\section{APPENDIX I}

A Summary of Lévy-Type Solutions Utilized in Free Vibration Analysis

\section{APPENDIX II}

A Brief Discussion of Fourier Series and Use of the Dirac Function.

\section{APPENDIX III}

Illustrative Computer Program

Index 